\title{
¿Migración o exilio cubano en Estados Unidos? \\ Notas para un debate
}

\section{Cuban Migration or Exile in the United States? Notes for Discussion}

\author{
Jorge Hernández Martínez*
}

Resumen: el objetivo de este artículo es analizar el proceso migratorio cubano cuya resultante conduce al surgimiento del exilio en Estados Unidos, luego del triunfo de la Revolución en la isla, en 1959. Toma en consideración los diferentes factores y condiciones que influyen en ese proceso y que explican su evolución hasta el presente. Se distingue entre la migración (como desplazamiento demográfico o traslado de personas y las comunidades que se establecen en Estados Unidos), y el exilio (como fenómeno esencialmente político). Como premisa, se considera que la dinámica migratoria cubana conducente al surgimiento del llamado exilio histórico no puede separarse de su desenvolvimiento real a través del tiempo, ni en su comprensión analíica del conflicto, ya prolongado por sesenta años, entre Cuba y Estados Unidos.

PalaBRAS ClavE: Migración; Exilio; Relaciones Cuba-Estados Unidos; Transición.

ABSTRACT: In specialized academic literature, the issue of Cuban migration and exile that is formed in the United States has been dealt with repeatedly, after the triumph of the Revolution on the Island, in 1959. Sometimes, both phenomena are discussed interchangeably, as if it were the same, and it is assumed to exile today in terms similar to those defined in its initial stage. The article analyzes the migratory process whose result leads to the emergence of said exile, takes into consideration the different factors and conditions that influence that process and explain its evolution to the present. A distinction is made between migration (as demographic displacement or transfer of people and communities established in the United States), and exile (as an essentially political phenomenon). As a premise, it is considered that the Cuban migration dynamics conducive to the emergence of the so-called historical exile cannot be separated from its real development over time, nor in its analytical.

Key WordS: Migration; Exile; Cuba-United States Relations; Transition.

Recibido: 04 de febrero de 2020

Aceptado: 25 de marzo de 2020

Universidad de La Habana (jhernand@ceseu.uh.cu). 


\section{INTRODUCCIÓN}

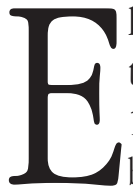

1 tema del exilio cubano, fundamentalmente el establecido en Estados Unidos a partir del triunfo de la Revolución en Cuba, en 1959, ha tenido un gran impacto en el desarrollo de las relaciones bilaterales entre los dos países y, en un sentido más amplio, en la dinámica de las relaciones interamericanas durante los últimos sesenta años. Su activismo político ha trascendido a la sociedad norteamericana, en la medida en que la influencia en América Latina y el Caribe de algunos de sus principales líderes y la presencia de determinadas organizaciones con base en territorio estadounidense gana espacios. Venezuela y México, República Dominicana y Puerto Rico son, en este sentido, algunos ejemplos representativos. Tales figuras y grupos han tenido un lugar, incluso, más allá de las Américas, como ha sido de modo destacado el caso de España y en menor medida - y mucho más acá en el tiempo- en los países europeos que formaron parte del campo socialista.

El exilio, sin embargo, es un fenómeno de connotaciones esencialmente políticas. Se nutre de procesos migratorios, y confluyen en él personas que abandonan su país de origen, en este caso, Cuba, por razones económicas, buscando espacios en otros mercados de fuerza de trabajo, explorando nuevos horizontes profesionales y espirituales, escapando de situaciones en las que podrían peligrar desde su posición social hasta el respeto a sus posiciones ideológicas, su integridad física, su vida. Desde este punto de vista, los condicionamientos histórico-temporales han repercutido en la configuración, composición, lugar y papel del exilio cubano que se conformó a inicios del decenio de 1960. Las circunstancias internacionales, intra e interamericanas, las de Cuba y Estados Unidos incluidas, han cambiado notablemente cuando se compara 1959 con 2019. En ese marco, las figuras que salieron de la isla siendo ya adultos, aunque también adolescentes y niños, han sufrido y experimentado el paso del tiempo. Han transcurrido sesenta años. La Guerra Fría, nacida al finalizar la Segunda Guerra Mundial, desapareció al desintegrarse la Unión Soviética, surgida con la Revolución de Octubre en 1917, y al desplomarse el 
campo socialista, formado a partir de 1945. La globalización y los procesos de regionalización e integración impactan a todas las sociedades. Se activan los fundamentalismos religiosos, se amplían los conflictos étnicos y nacionales, los escenarios bélicos, el terrorismo, se dinamizan la sociedad civil y los movimientos sociales en todas las latitudes; se expanden las crisis económicas, políticas, ecológicas. Junto a ello, entre otros procesos relevantes, los procesos migratorios prosiguen, desde todas y hacia todas partes, si bien, los migrantes que se desplazan del Sur hacia el Norte conservan su protagonismo en una dinámica de continuidades y cambios en cuanto a motivaciones, patrones, políticas gubernamentales de rechazo y acogida. La importancia de las fronteras en el terreno de las relaciones internacionales y los derechos humanos se mantiene en primeros planos. Y en este amplio y esquemático paisaje, persiste el histórico y prolongado conflicto entre Cuba y Estados Unidos, en el cual la migración originada en la isla y establecida en el poderoso vecino del norte sigue apareciendo como una constante, bajo nuevos parámetros. La trayectoria del proceso migratorio cubano, a la luz del presente, ha cambiado. Hoy día, podría decirse que el exilio cubano aludido al inicio -el identificado en la literatura especializada de la sociología y la ciencia política, también en el periodismo, como exilio histórico- se halla inmerso en un avanzado proceso de transición, que cada vez más deja atrás sus rasgos principales, los que lo definían en tanto exilio, y se ha convertido, de manera creciente, en una comunidad de migrantes, al estilo de tantas otras que conviven en Estados Unidos (y en otros de los países mencionados), abandonando la escena política el viejo liderazgo fundacional de las organizaciones creadas en la década de los sesenta y aun después, entre desapariciones físicas, disminución de capacidades de influencia, pérdida de presencia en círculos intelectuales, anquilosamiento público y anacronismos ideológicos, avanzados envejecimientos de quienes llegaron hace seis o cinco décadas, arribo a la adultez de los que nacieron allí y significativas inyecciones de nuevos migrantes. La combinación de esos y otros procesos, concernientes a la sociedad norteamericana anfitriona, conducen a la transición señalada. De 
ahí que quizás resulte más objetivo, realista y preciso, hablar en la actualidad de la migración que del exilio cubano en Estados Unidos.

El tema de ese exilio ha mantenido una importancia renovada, en la medida en que la migración cubana ha sido una pieza funcional en el diseño de la política norteamericana hacia la Isla, y que el exilio se ha proyectado tradicionalmente contra la Revolución Cubana, procurando influir en tal política. Esta realidad acompaña a las acciones generadas por los gobiernos de Estados Unidos a través de seis décadas, desde Dwight Eisenhower hasta Donald Trump.

Se parte de la premisa de que la naturaleza de dicha migración, así como la del exilio resultante, se explica en el marco de la nombrada Guerra Fría por la confluencia de múltiples factores relacionados con la dinámica interna en los dos países. Se asume la hipótesis, en parte ya anticipada, según la cual el exilio cubano se ha ido transformando bajo el impacto acumulado de circunstancias diversas (asociadas a su dinamismo sociodemográfico, a los contextos políticos en ambos países y al conflicto que caracteriza su relación bilateral, así como a las tendencias migratorias que han tenido lugar desde finales del siglo pasado), como resultado de lo cual se han desdibujado hoy sus características iniciales. Esa conjunción de factores ha ido condicionando una transición política e ideológica en lo que fue el exilio histórico tradicional, cuyo protagonismo, peso y perfiles han ido perdiendo presencia, para mutar hacia un grupo étnico y luego, más hacia acá en el tiempo, hacia una comunidad de inmigrantes (Hernández 1997; Castro 1998).

Y es que en la medida en que transcurrió el tiempo, la migración cubana externa más reciente - en general, y hacia Estados Unidos en particular-, experimenta un cambio cualitativo: de una migración política transita a una económica y familiar. En este sentido, el patrón migratorio cubano va perdiendo las particularidades que le definen a comienzos de la década de los sesenta, acercándose cada vez más al del resto de los países latinoamericanos y caribeños.

Sin embargo, el desarrollo de esa tendencia no ha impedido que determinadas figuras de ese exilio hayan conservado capacidad individual de 
influencia y presión y logrado insertarse en las estructuras del sistema político norteamericano, desempeñando un papel relevante dentro de gobiernos conservadores republicanos en el siglo en curso, como los de George W. Bush y Trump. Algunos de ellos han adquirido notable visibilidad nacional, promoviéndose incluso con aspiraciones a la presidencia en ciertas contiendas electorales, o como congresistas, en el Senado y la Cámara de Diputados, así como en el escenario más limitado, del estado de la Florida. Pero no han contado con un auspicio institucional de las organizaciones del exilio, que antes fungían como destacadas cajas de resonancia, y cuya vida política pública ha perdido dinamismo y capacidad de convocatoria, toda vez que circunscriben sus actividades al ámbito donde se concentran espacialmente los migrantes y sus descendientes.

Es importante sustraerse, desde la perspectiva de los estudios americanos, afincada en las ciencias sociales, al análisis de las coyunturas. Y en tal sentido, a la coyuntura más reciente y relevante, la que se crea en la relación bilateral Cuba-Estados Unidos a partir del 17 de diciembre de 2014 - que inicia una efímera fase de deshielo y mejoramiento, con restablecimiento de lazos diplomáticos durante el último periodo de la segunda administración de Barack Obama-y el retorno a las crecientes tensiones bajo la presidencia de Trump, que interrumpe ese proceso, con el impulso desde las ramas ejecutiva y legislativa de influyentes políticos del exilio cubano y de la extrema derecha estadounidense. De ahí la pertinencia de una interpretación histórico-sociológica panorámica, a la luz del siglo XXI, que se detenga con criterios selectivos sólo en determinados momentos, procesos y etapas.

LA MIGRACIÓN CUBANA: UNA APROXIMACIÓN GLOBAL

La migración de cubanos hacia Estados Unidos no es un fenómeno que comienza con la Revolución en 1959. Se remonta a principios del siglo XIX, llegando a ser la más nutrida de las migraciones latinoamericanas a ese país, después de la mexicana, hasta los años de 1860. Se trataba de un pro- 
ceso que, a manera de constante, se registraba incluso con anterioridad a que Cuba alcanzara su condición, en términos históricos estrictos, como Estado-Nación (Arboleya 2013).

Por consiguiente, esa migración, con destino fundamental en la sociedad norteamericana, es un proceso de larga data en la historia nacional de la mayor de las Antillas. Aunque sus antecedentes se remontan al siglo XIX, alcanzan su intensidad máxima en el XX, bajo el condicionamiento de factores económicos y políticos, cuya expresión más notable - tanto en el plano objetivo o de la práctica social, como en el subjetivo, concerniente a su reflejo y manipulación a través de los medios periodísticos, de los estudios de las ciencias sociales y de los discursos gubernamentales en los dos países aludidos - tiene lugar a partir del triunfo de la Revolución cubana, a comienzos de 1959.

Ese proceso migratorio posee características singulares, que le diferencian un tanto del que se gesta en otros escenarios de América Latina y el Caribe, que tienen en común a Estados Unidos como principal anfitrión, si bien las causas que lo motivan se distinguen, durante la mayor parte del tiempo transcurrido desde entonces, por su sobresaliente gravitación política, tanto desde el punto de vista de los acontecimientos en la isla como del tratamiento preferencial que le otorga a los migrantes cubanos la política general (y en especial, la migratoria) estadounidense, en fuerte contraste con la que se aplica a los que proceden del Caribe insular y, más ampliamente, de la América del Sur que a nivel continental se extiende al sur del Río Bravo (Aja 2014).

En el presente, el escenario de la migración internacional está marcado por el incremento de la perspectiva de selectividad ante el arribo de los inmigrantes, su vinculación con la seguridad nacional de los Estados, y la necesidad de protección ante problemas como el narcotráfico, el terrorismo internacional y el tráfico ilegal de personas. La tendencia a la migración de profesionales denota la creciente selectividad de las políticas y regulaciones migratorias de los diferentes países, proceso en el que se advierte un predominio de migrantes jóvenes y una suerte de feminización de la migración, signado por el envejecimiento de las poblaciones 
de los principales países receptores y la contribución circunstancial de los migrantes al crecimiento demográfico, en particular de la población económicamente activa de esas naciones. Otras son las consecuencias para los países emisores, como regla, subdesarrollados y periféricos, cuyo comportamiento demográfico se afecta con la pérdida, resultante de la emigración de personas en plena capacidad laboral y de potencialidad reproductiva, particularmente cuando se refiere a hombres y mujeres jóvenes.

Así, los desplazamientos humanos desde el Sur hacia el Norte tienen lugar en correspondencia con la tendencia de los flujos migratorios, de producirse desde lugares con menor desarrollo a otros comparativamente superiores. De ahí que se mantengan, en lo fundamental, los principales destinos históricos de la migración internacional y que, a la vez, se diversifiquen los países de recepción y tránsito de los migrantes, si bien en las Américas permanezca Estados Unidos en el sitio principal.

En ese marco general, se refuerza la multicausalidad de los movimientos migratorios: causas económicas, expectativas de mejores condiciones de vida, reunificación familiar, papel de las redes familiares y sociales, así como las ventajas comparativas de la inserción laboral y socioeconómica entre las sociedades de destino y origen (Aja 2014).

En la magnitud del flujo desde la región latinoamericana y caribeña ha sido determinante la posición y actuación de Estados Unidos a través del tiempo, si bien en la actualidad, bajo el gobierno republicano y conservador de Donald Trump y de su orientación antinmigrante, discriminatoria, racista y xenófoba, encaminada especialmente al férreo control de su frontera sur, como principal paso de los migrantes de la región. Lo acontecido hasta el momento indica que la porosidad y extensión de esa frontera, la mexicana, se combina con la de la política migratoria estadounidense y su aplicación por el actual gobierno, marcado por la impredecible conducta presidencial.

En el contexto migratorio regional y global, los migrantes actuales y los que le sucederán responden a patrones migratorios y de inserción con más similitudes que diferencias. Así, se refuerza la tendencia a los desplazamientos temporales, a la incorporación al mercado laboral en los secto- 
res de los servicios, la construcción y el comercio, hacia ciudades grandes y a otras con ventajas comparativas a los lugares de origen. Las relaciones transnacionales se fortalecen, donde el protagonismo de las remesas marca pautas en los vínculos entre países, territorios, poblaciones y familias. Justamente, en ese entorno se ubica hoy el proceso migratorio cubano, en la medida que de manera creciente se acerca cada vez más al patrón migratorio latinoamericano y caribeño tradicional, del cual se apartaba a lo largo de muchas décadas, en la medida en que éste se caracterizaba por el predominio de razones económicas de los migrantes, junto al envío de remesas, el retorno, la circularidad; en tanto que la migración cubana era impulsada por factores políticos, la ruptura de relaciones con la isla y por un carácter definitivo, todo lo cual conducía a la definición de las comunidades de cubanos establecidas en Estados Unidos - y en otros países, como España y Venezuela, en los años de 1960 a 1970-, como un exilio.

EL EXILIO Y EL CONFLICTO HISTÓRICO ENTRE CUBA Y ESTADOS UNIDOS

La Revolución que triunfa en Cuba en 1959, ya se ha señalado, constituyó un punto de inflexión en el desarrollo histórico de las tendencias migratorias, al propiciar cambios radicales en la esfera política, económica, social y cultural que alteraron la estructura de clases, las relaciones de propiedad y el imaginario o mundo subjetivo en esa nación. Así, la migración internacional de la isla pasó de ser un proceso con retornos, de connotaciones principalmente económicas o laborales (que involucraba a desempleados, subempleados y soñadores que buscaban espacios en el mercado de la fuerza de trabajo en el extranjero), educativas (que comprendía a personas cuyas posibilidades materiales les permitían realizar estudios universitarios en ese país) y turísticas (con una temporalidad limitada), con una baja proporción de sujetos que eran perseguidos por oponerse a la dictadura de Fulgencio Batista a través de acciones revolucionarias, a una básicamente política y de carácter definitivo. Con ello, la migración rede- 
finía las formas de interacción y las relaciones entre los migrantes y la sociedad cubana, a través de movimientos masivos que tenían como destino principal a Estados Unidos, con frecuencia apelando a acciones furtivas.

Prácticamente de inmediato, durante el propio 1959 y durante la década siguiente, tiene lugar un drenaje migratorio que se manifiesta con intermitencia a través de oleadas, bajo el estímulo de la política de Estados Unidos, cuyos gobiernos sucesivos, hasta decenios posteriores, que se prolongan hasta el siglo XXI, incentivan la migración ilegal. De ahí que la dinámica migratoria cubana, conducente al surgimiento de un exilio histórico cuyo asentamiento central se establece en el mencionado país, no puede separarse en su desenvolvimiento histórico real ni en su comprensión analítica, del conflicto, ya prolongado por sesenta años, entre Cuba y Estados Unidos (Domínguez 2015; Hernández 2015).

Tanto el proceso migratorio implicado como el exilio de él derivado, así como la situación del país emisor y del receptor de esa migración, han cambiado a lo largo de los seis decenios que han transcurrido. La migración es la resultante histórica de un proceso de prolongada presencia en la sociedad cubana, donde se conjugan, como ya se ha señalado, muy diversos factores: políticos, económicos, sociales e ideológicos, entre los que se incluyen condicionantes y características objetivas y subjetivas. En el caso de Cuba, ese proceso comienza a desarrollarse en el marco de una situación económica y contradicciones políticas que caracterizaban la realidad de la isla desde el siglo XIX, a partir de 1860, en la medida en que se agudizan los conflictos entre la sociedad colonial cubana y la metrópoli española. Una parte significativa de dicha migración, establecida en Estados Unidos, daría lugar a una comunidad exiliada, atendiendo a la situación política que obligó a figuras de relieve a establecerse en dicho país, y a la connotación patriótica de sus actividades allí, en función de la organización y apoyo al proceso independista en la isla.

La dinámica migratoria proseguiría durante la primera mitad del siglo xx, en el seno de la sociedad neocolonial cubana y bajo el condicionamiento de la hegemonía y cercanía geográfica del vecino del Norte. Así, a finales de la década de los cincuenta, se calculaba que la población cu- 
bana en ese país alcanzaba aproximadamente entre 50 y 60 mil personas, muchas de las cuales buscaban allí horizontes económicos que ofrecía el mercado laboral. Los cálculos establecidos por la historiografía fijan a fines de ese siglo una cifra aproximada de 25 mil cubanos en Estados Unidos, radicados fundamentalmente en regiones del sur y del noreste norteamericano (Aja 2014).

Han transcurrido seis décadas desde que a partir del triunfo de la Revolución Cubana en 1959 se despliega una significativa migración que tiene como principal destino a Estados Unidos y a la ciudad de Miami, en el estado de Florida, si bien un gran número de cubanos se iría radicando también en otros centros urbanos de ese país, así como en España y Venezuela. Como denominador común, esos primeros migrantes salieron de la isla en un marco de confrontación ante los profundos cambios que se estaban produciendo, que incluían la expropiación de tierras, negocios, industrias y la nacionalización de la economía nacional.

Tras ese éxodo inicial comienza un proceso que se mantiene de forma prácticamente constante, que acrecienta de manera vertiginosa la conformación de comunidades o asentamientos de cubanos en dichos países, que se extendían a otras ciudades norteamericanas, como las de Hialeah, en el estado mencionado, Union City y West New York, en el de New Jersey, y las de Madrid y Valencia, respectivamente, en España y Venezuela. El resultado básico de ese drenaje migratorio, más allá de constituir un proceso demográfico, como movimiento internacional de personas, fue de carácter político. De cierta manera, se trataba de una migración forzosa, en la medida que las razones y motivaciones de los implicados implicaban la búsqueda de refugio, al ser enjuiciados unos por la legalidad revolucionaria, resentidos otros por la pérdida de propiedades, junto a familias atemorizadas por la orientación política radical que se prefiguraba aun antes de que oficialmente se declarara el carácter socialista de la revolución en 1961.

Ese proceso - desarrollado a través de un flujo migratorio sistemático, que comprendió fases de mayor intensidad, cual oleadas que en circunstancias de crisis llevaron consigo desplazamientos masivos signi- 
ficativos-, fue estimulado desde muy temprano por la política de Estados Unidos, al identificarse a la migración como una pieza funcional en el diseño y puesta en marcha de un proyecto subversivo enfilado contra la Revolución cubana. Es en tal contexto que se ubica el surgimiento del exilio cubano contemporáneo, es decir, el que se configura como consecuencia de las radicales y profundas transformaciones políticas que bajo el liderazgo de Fidel Castro se desatan en la isla a partir del primero de enero de 1959.

Considerado en la literatura sociológica y politológica especializada como el "exilio histórico", se trata de un fenómeno cuya articulación data desde ese mismo año y comienzos de la década de los sesenta, con el establecimiento en las mencionadas ciudades de grupos de migrantes o de comunidades de cubanos, que en su mayoría procedían de la burguesía, la pequeña burguesía y otros sectores que fueron afectados por las nuevas leyes revolucionarias, junto a militares y en general, personal vinculado a las estructuras políticas y castrenses del gobierno dictatorial que encabezaba el presidente Fulgencio Batista.

El naciente exilio, por tanto, no era homogéneo. Desde el punto de vista de su composición social y clasista se conformó por segmentos diversos de la sociedad cubana, predominando los nombrados, pero abarcando también una amplia gama de individuos y familias completas, provenientes tanto de capas medias como de trabajadores, empleados en muchos casos en la esfera de los servicios y en labores domésticas, en cuyos mundos subjetivos se mezclaban diversos motivos: inseguridad, temor, rechazo y cierto contagio psicológico o reacción imitativa, ya que no pocos se marchaban del país siguiendo el ejemplo de patrones, amistades y vecinos, sin convicciones políticas definidas. Los estereotipos y prejuicios existentes entonces sobre el comunismo y sus excesos estaban generalizados en el contexto social e ideológico de la sociedad cubana, como en muchas otras partes de América Latina, en las que las clases dominantes representadas por los gobiernos de turno divulgaban e imponían a través de los aparatos ideológicos del Estado: instituciones educativas, culturales y formadoras de la opinión pública, como la televisión, la radio, unidas a productos del 
arte como el cine, las historietas gráficas y tiras cómicas (Grenier y Pérez 2003). Quienes habían nutrido en la isla las filas de las nacientes organizaciones opositoras contrarrevolucionarias, y terminado en prisión, neutralizados por los órganos de la seguridad estatal cubana, integrarían, al ser liberados, el núcleo del éxodo migratorio y serían componentes centrales en la estructuración del citado "exilio histórico", creando agrupaciones políticas y medios de comunicación que organizaban o incentivaban actividades dirigidas a derrocar la Revolución y al retorno al país, algunas de ellas con una definida connotación terrorista, fijando una notoria cultura de intolerancia, un clima de presión psicológica en las comunidades de migrantes cubanos, que creaba o imponía un consenso frente al cual no cabía la discrepancia (Arboleya 2013).

\section{MIGRACIÓN Y EXILIO \\ EN LA POLÍTICA NORTEAMERICANA}

Así, la política gubernamental de Estados Unidos estableció, prácticamente desde el triunfo mismo de la Revolución cubana, un esquema subversivo intervencionista que ha mantenido vigencia, adquiriendo relieves descollantes en determinadas etapas, como las de Eisenhower, Kennedy, Nixon, Reagan, W. Bush, Obama y Trump, tanto durante administraciones demócratas como republicanas, liberales o conservadoras, entre variantes que han aplicado en unos casos el "poder duro" (bloqueo, asfixia económica, aislamiento diplomático internacional, actos terroristas, negación de visas), en otros el "blando" (influencia ideológica, robo de cerebros, intercambios académicos, culturales, deportivos, religiosos, relaciones pueblo a pueblo, otorgamiento de visas), apreciándose con frecuencia la combinación de ambos métodos.

En ese esquema se identificó con precocidad la utilización de la migración como un instrumento subversivo, al incitar por un lado la salida ilegal de la isla mediante la creación del Programa de Refugiados y la Ley de Ajuste Cubano, a comienzos de la década de 1960, como vía de deses- 
tabilización del proceso revolucionario, y al propicia por otro el uso de las organizaciones del exilio para la realización de acciones de infiltración dentro de territorio cubano con el propósito de estructurar la contrarrevolución interna, llevando a cabo actos de sabotaje y atentados a los líderes revolucionarios. En ese contexto, el accionar del exilio histórico se vio beneficiado con la imagen de no pocos exponentes relevantes de la intelectualidad cubana que pusieron sus nombres al servicio del sistema ideológico de propaganda que denigraba a la Revolución y condenaba, por cobardía o traición patriótica, a sus homólogos - escritores y artistas-que decidieron quedarse en la isla. Esta tendencia no fue monolítica ni en todos los casos implicó una manipulación maniquea del gobierno estadounidense, pero contribuyó a cohesionar la ideología predominante en dicho exilio y a fomentar la intransigencia en las comunidades de cubanos emigrados. Figuras como las de Guillermo Cabrera Infante y Jesús Díaz, en diferentes tiempos, abonaron a la construcción de esa historia.

A través del tiempo, tales organizaciones ganaron en membresía, visibilidad y papel político en la vida local en los asentamientos mayores de migrantes, como Miami, Hialeah, Union City, Valencia, Madrid, conformando una red contrarrevolucionaria subordinada a, o insertada en, la política exterior norteamericana (Rodríguez 2000). En ello que sobresalían Alpha 66, Omega 7, el Movimiento 30 de Noviembre, los Comandos L, la Junta Patriótica Cubana, el Partido Socialdemócrata Cubano, la Coordinadora de Organizaciones Revolucionarias en el Exilio (CORU), Recuperación Cubana en el Exilio (Rece), la Plataforma Democrática Cubana, Los Municipios de Cuba en el Exilio, Hermanos al Rescate y la Fundación Nacional Cubano-Americana (FNCA), entre las principales, con personajes destacados como Eloy Gutiérrez Menoyo, Andrés Nazario, Hubert Matos, Jorge Más Canosa, Jorge Más Santos, algunos de los cuales, como Mario y Lincoln Díaz Balart, Ileana Ross-Lethinen, Robert (Bob) Menéndez, Marcos Rubio, Ted Cruz, quienes en fechas relativamente recientes y muy recientes, se ubican en estructuras legislativas y sobresalen en ámbitos políticos estaduales y nacionales, así como en círculos empresariales y financieros, con capacidad, además, de influencia económica. Como regla, mantuvieron la 
intención de incidir en la toma de decisiones con respecto a Cuba en las instancias del gobierno de Estados Unidos, y con frecuencia, la literatura académica y la prensa especializadas han sobrestimado ese alcance, afirmando incluso, con cierta asiduidad, que la política estadounidense hacia la Revolución no se fabricaba en Washington, sino en Miami. La historia ha demostrado, sin embargo, en más de una ocasión, que ante circunstancias críticas en las relaciones bilaterales entre Estados Unidos y Cuba, en las que la FNCA y otras organizaciones presionaron de manera descollante e histérica - procurando que se interrumpieran acuerdos entre los dos gobiernos encaminados a solucionar problemas de la mayor importancia (la pacificación en el cono Sur africano en 1988, que implicaba el cese del apoyo militar norteamericano a Sudáfrica, la retirada de las tropas cubanas de Angola y la independencia de Namibia, y la firma del Acuerdo Migratorio para resolver la crisis migratoria de los balseros, en 1994)-, lo que prevaleció fue la razón de Estado. Con ello lo que se quiere subrayar es que la política de Estados Unidos hacia Cuba ha dependido mucho más de la raison d' Etat norteamericana, es decir, de los intereses permanentes de las elites de poder, que de los objetivos de una u otra administración de turno (demócrata o republicana, en términos partidistas, liberal o conservadora, en términos ideológicos), o de los propósitos de los grupos de presión del exilio cubano, al estilo de la FNCA. Cuba es considerada, por consiguiente, en el expediente de ayer y de hoy del sistema político de Estados Unidos, como un asunto que concierne tanto a su política interna, con una connotación simbólica, como a la orientación pragmática de su proyección exterior.

En los ejemplos aludidos se concretaron procesos de diálogo y concertación jurídica, a contrapelo de las presiones del exilio, cuyas argumentaciones acusaban al gobierno de Estados Unidos de traición al exilio, al negociar con un ilegítimo cadáver político a las autoridades estatales cubanas.

Como complemento del mapa político del exilio, de manera paralela al desarrollo de las organizaciones representativas de la ideología contrarrevolucionaria dominante, y con mucha menor fuerza y presencia, nacen 
también de modo paulatino otras, portadoras de voces alternativas desafiantes, como la Brigada Antonio Maceo, la Alianza de Trabajadores Cubanos y la Alianza Martiana, donde se hicieron conocidas figuras como la de Carlos Muñiz Varela, asesinado por grupos terroristas, Francisco Aruca y Andrés Gómez, este último muy activo, en constantes viajes entre Miami y La Habana.

La FNCA ha sido quizás, en ese contexto, la organización más conocida, que logró introducirse en el sistema político norteamericano, en los medios de Washington, como lobby o grupo de presión, con el apoyo de la administración republicana de Ronald Reagan en la década de 1980, que mantuvo su protagonismo más allá de la muerte de Más Canosa, dados los vínculos de amistad personal de su hijo, Jorge Más Santos, con los hijos de quien fuese el vicepresidente de Reagan durante ocho años, y luego presidente por un único mandato, el también republicano George H. Bush (Pérez 2014).

En la década de los noventa, en la presidencia del demócrata William Clinton, las presiones del exilio cubano condicionaron notablemente la política de Estados Unidos hacia Cuba, al aprobarse la Ley Torricelli en 1992 y la Ley Helms-Burton en 1996, que reforzaron las regulaciones y restricciones establecidas por el bloqueo desde su nacimiento, al imprimirle un carácter extraterritorial, que agregan una verdadera persecución financiera transnacional a los intentos de Cuba por ampliar sus espacios y relaciones comerciales en Europa y otras latitudes.

La FNCA renace bajo el doble gobierno de George W. Bush y la gobernatura en el estado de Florida de su hermano, Jeb Bush, ambos de la misma afiliación partidista que su padre. Sin embargo, la declinación institucional de la pujanza del exilio tradicional comienza a percibirse desde los inicios del presente siglo, a partir de la confluencia de diversos factores, cuyo papel se intensifica en las dos últimas décadas. Hoy día, la mayor parte de las organizaciones mencionadas ha disminuido su repercusión pública, capacidad de influencia gubernamental y de movilización popular entre los emigrados. 


\section{¿MIGRACIÓN O EXILIO CUBANO EN ESTADOS UNIDOS?}

Aunque ha tenido lugar sin anuncios previos y oficiales, como es la práctica gubernamental acostumbrada ente situaciones tan sensibles como las vinculadas a las políticas migratorias, el presidente estadounidense, Donald Trump, de hecho ha suspendido en los dos últimos años la marcha de los acuerdos migratorios establecidos desde 1994, a raíz de lo que se conoció entonces como "la crisis de los balseros", que a causa de la difícil situación económica en la isla produjo la desaparición de la Unión Soviética y del campo socialista en Europa Oriental, lo que afectó sustancialmente un flujo de migrantes que alcanzaba aproximadamente a veinte mil personas anuales.

En ese contexto, las visitas de cubanos residentes en la isla a familiares en Estados Unidos se verían, a la vez, afectadas: en la práctica se redujeron a su mínima expresión, como resultado del cierre de las oficinas consulares norteamericanas en Cuba. Por otro lado, se registra desde entonces una visible ralentización en la aplicación de la vieja Ley de Ajuste Cubano, lo que impacta en el estatus legal de miles de migrantes, que llegan a la sociedad estadounidense, "la tierra prometida", la del "sueño americano", procedentes de Cuba en los últimos años.

No puede obviarse, en el cuadro descrito, la cancelación realizada por el gobierno de Barack Obama en 2017, de la conocida política establecida por Estados Unidos desde el decenio de 1990, relacionada con la crisis mencionada, según la cual si el cuerpo de guardacostas de dicho país interceptaba y capturaba en alta mar a los migrantes que en rústicas e inseguras embarcaciones (en su mayoría se trataba de balsas y pequeños botes), los regresaba a la isla, en tanto que aquellos que alcanzaban el territorio estadounidense eran admitidos y bienvenidos. Se trata de la interrupción de la política denominada "de pie seco/pie mojado", que hasta esa fecha favorecía la permanencia de migrantes ilegales cubanos en Estados Unidos. De ese modo, de manera inesperada y vertiginosa, los migrantes cubanos transitan de ser los más privilegiados de Estados Unidos, a uno de los grupos más restringidos del mundo. Con ello, se 
pierde buena parte del condicionamiento que hacía de la migración cubana un exilio. En esta situación ha confluido el hecho de que los políticos identificados como "cubanoamericanos", en realidad han sido cada vez más norteamericanos y cada vez menos cubanos, al tratarse en muchos casos de individuos nacidos en Estados Unidos, y en otros, de personas que salieron de Cuba en edades muy tempranas y se fueron insertando en las estructuras sociales, económicas, políticas y culturales de ese país. En esa medida, han ido perdiendo la funcionalidad que tenían en el diseño de una proyección gubernamental que alimentaba, en términos objetivos y subjetivos, la imagen de un exilio dorado. Las premisas que condicionaban la excepcionalidad del lugar de los migrantes cubanos en la sociedad norteamericana, así como el carácter preferencial de la política de Estados Unidos hacia las comunidades de cubanos allí asentadas, habían cambiado. En resumen, lo que está sucediendo en la actualidad es un proceso de dirección contraria. Lo que resulta funcional o conviene a los políticos de la derecha cubanoamericana y al enfoque gubernamental de Trump es que lleguen pocos migrantes cubanos a territorio nacional y que se demoren en avanzar en el proceso de obtención de la residencia permanente de la ciudadanía, y del logro de una inserción ágil en las estructuras socioeconómicas, políticas y culturales de ese país.

En ese cambio influye, también, el interés estadounidense de promover o estimular las tensiones políticas y sociales en Cuba, asumiendo el punto de vista de que al limitar las posibilidades migratorias, se propicia la tendencia a "aumentar la presión en la caldera doméstica" en la isla, para fomentar descontento y posturas de oposición y enfrentamiento al gobierno cubano.

Sin embargo, para Cuba lo más preocupante no son las dificultades para viajar como resultado de la política norteamericana, sino que, aun así, los niveles migratorios continúan siendo muy altos, sobre todo entre los jóvenes en plena capacidad laboral. Se trata de un fenómeno endógeno, relacionado con la situación económica del país y la satisfacción de las expectativas existenciales de estos sectores, por lo que su solución rebasa las posibilidades de cualquier política migratoria. Por cierto, en Cuba no 
se han establecido en este reciente entorno nuevas restricciones migratorias -luego del proceso de flexibilización y apertura migratoria que tuvo lugar en los últimos años-, el flujo de migrantes hacia otras partes tiende a compensar las limitaciones impuestas por Estados Unidos y los niveles de salidas ilegales se mantienen bajos, lo que ha garantizado cierta estabilidad interna alrededor de este tema.

Los déficits de la política migratoria cubana ya no están referidos a los procesos de salida y entrada al país, sino al tratamiento a los emigrantes durante su estancia en el extranjero. Los cambios en la aludida política, adoptada a partir de 2013, tienden a resolver el vínculo legal con el país de aquellas personas que emigraron desde esa fecha, aun y cuando se mantengan las restricciones para los que salieron con anterioridad.

En la actualidad, bajo el gobierno de Trump, es notorio el papel de varias figuras de origen cubano (cuya identidad, según se indicaba, se define mejor como de estadounidenses que de cubanoamericanos), que fundamentalmente desde las filas del Partido Republicano y las instancias parlamentarias están desempeñando una influencia decisiva en el enfoque de la hostil política hacia Cuba y, en general, en la orientación de extrema derecha que distingue a la política de Estados Unidos hacia los procesos y gobiernos progresistas, emancipadores y antimperialistas en América Latina. Algunas de ellas aspiraron por el mencionado partido, incluso, a la nominación presidencial. A partir de ahí, se ha tratado con atención el tema en no pocos medios intelectuales y periodísticos, pues se considera que el exilio cubano ha adquirido una energía política renovada.

En rigor, esta última apreciación sobredimensiona la envergadura cualitativa de dicho exilio, basada en una percepción errónea, que magnifica el papel de determinados individuos (Marcos Rubio, Mauricio Claver-Carone, Lincoln y Mario Balart, Ted Cruz) que, si bien cuentan con respaldo partidista y gubernamental y han aprovechado de modo oportunista determinados espacios y ocupado posiciones institucionales, ello no es representativo de un exilio, como fenómeno sociológico, cuyo sujeto político se halla notablemente envejecido desde el punto de vista demográfico y generacional, con reducidas bases de sustentación social, con un 
discurso autoritario e intolerante que era típico del "exilio histórico", que ha ido perdiendo resonancia y capacidad de movilización a nivel popular. Su proyección retórica se ha quedado como congelada, saturada de definiciones estáticas, anacrónicas, acompañadas de rigidez, dogmatismo e intransigencia, con un pobre activismo político efectivo. Lo que está sucediendo es una consolidación del proceso que venía caracterizando en los últimos decenios el cambio en ese exilio inicial.

En resumen, y como ya se ha señalado, desde la década de los noventa y hasta el presente, se ha ido modificando su naturaleza, y de manera gradual, aquel exilio se ha transformado en una comunidad de inmigrantes, primero, y en un grupo étnico, después. Así, se visualizan señales de nuevas tendencias. El exilio cubano se halla hoy en plena transición.

La vida política de la emigración cubana -durante la última década del siglo xx y las dos que han transcurrido en el actual, tanto en Estados Unidos como en España y Venezuela, como principales sociedades anfitrionas, pero a las que se han ido sumando otras, como la mexicana, entre muchas otras, con menores concentraciones de migrantes-, se caracteriza, en sentido general, por un gran dinamismo, por frustraciones, búsquedas, aperturas y cierres, posiciones de moderación política, intereses en la relación con la isla, por encima de su gobierno, en mantener las visitas, junto a posturas de intolerancia y dogmatismo, ancladas en la tradición ideológica inicial del exilio histórico. Ello tiene lugar, desde luego, en estrecha relación con lo que ocurre en Cuba, en la medida que las diferentes percepciones que coexisten en la migración se construyen a partir de los procesos internos en la Isla. En este sentido, se aprecian distintas tendencias en el arco ideológico del llamado Miami cubano, asumiéndolo como epicentro de la migración cubana en su conjunto - aunque no sea representativo de los procesos de cambio que tienen lugar en ese universo-, sobre la base de la gravitación ideológica de los sectores de poder que allí aún predominan, cuyo control de los medios de comunicación impone su visión e intereses, a contrapelo de aspiraciones de crecientes segmentos de población cubana, que desde el extranjero se interesan en 
normalizar sus relaciones con su país de origen, a partir de intereses tanto familiares como económicos y políticos.

Los procesos son contradictorios. Por un lado, la sobrevivencia de la Revolución, en medio de enormes dificultades, ha fortalecido la convicción de los segmentos minoritarios del exilio histórico, acerca de que es necesario utilizar el estrangulamiento económico y la vía violenta como solución definitiva, en contubernio con un gobierno norteamericano como lo fueron ayer, en sus momentos, el de Reagan y W. Bush, como lo es hoy el de Trump.

Por otro, la ya vieja experiencia de Europa del Este ha seguido alimentando las esperanzas de que con recetas similares se lograría la llamada "transición" pacífica al capitalismo en Cuba. Esto ha sostenido a aquellos proyectos que tratan de presionar internacionalmente a la Revolución a través de gobiernos y partidos políticos en Europa y América Latina, al tiempo que estimulan la oposición supuestamente "civilizada, no violenta", dentro de Cuba, que por cierto, ha ido perdiendo dinamismo, legitimidad, credibilidad y membresía, sin capacidad alguna real de impulsar cambios políticos en el país.

Ante la dinámica interna en la isla, que incluye en medio de muchos e importantes apuros cierta reanimación económica relativa, reformas del trabajo por cuenta propia, una significativa reinserción internacional, la flexibilización de la política migratoria y hacia la emigración, y una definida capacidad de resistencia ante el hegemonismo estadounidense, se crean condiciones que favorecen la expectativa y las tendencias y organizaciones del mundo emigrado (Domínguez; Machado; Delgado 2016).

Ellas se distancian de las alternativas dogmáticas e intransigentes del exilio histórico, y promueven opciones desde la moderación y el respeto a las diferencias, comprometidas con la soberanía nacional. Exponentes de estas tendencias han incrementado y mantenido sus vínculos con Cuba durante los últimos años, y cuestionan la política de Trump, que limita o impide visitas y remesas, bajo la presión de exponentes del exilio cubano que le estimulan y acompañan. 
A pesar de todo, las visitas a Cuba por parte de los emigrados se mantienen. Otro tanto sucede con el envío de remesas a los familiares en la isla, que sortean obstáculos, con gran capacidad imaginativa y burlan la legalidad norteamericana, asumiendo, claro está, riesgos legales. En Miami, como en otras áreas donde se concentran comunidades relevantes de cubanos en el exterior, pueden comprarse desde hace más de dos decenios los CDs con la música de los más destacados músicos cubanos, no pocos de los cuales viajan a esa y a otras ciudades estadounidenses con reiteración, y DVDS con las películas más recientes, facturadas en Cuba. Escritores, artistas y académicos emigrados o exiliados participan ya habitualmente en eventos culturales o científicos en la isla.

Los procesos que viven la migración y el exilio, en efecto, son complejos y contradictorios. Estas características se incrementan con la diversidad creciente que define al proceso migratorio en la actualidad, a partir de las constantes llegadas a Estados Unidos y otros países de personas de la isla, muchas de ellas nacidas después de 1959, quienes se han socializado y educado bajo la influencia de la Revolución, y a pesar de lo que probablemente quisieran, no pueden escapar totalmente a ese condicionamiento objetivo.

A ello se suma la presencia que van adquiriendo en la vida social, cultural y económica de lo que ya no sería un "exilio histórico", los jóvenes de segunda o tercera generación (hijos o nietos de los emigrados de los años de 1960, 1970 y 1980), que ya se han hecho adultos o al menos adolescentes, quienes no conocieron directamente la sociedad cubana, no la han visitado, sino que tienen una imagen legendaria de la isla, a partir de las historias, recuerdos y vivencias de sus familiares. Estos jóvenes, por tanto, como en parte es el caso de los balseros y de los que llegan a Estados Unidos mediante el sorteo, no se proyectan, en lo fundamental, con la obsesión ni el resentimiento hacia la Revolución de sus padres o abuelos. Y en el caso de aquellos que han dejado en Cuba, en fechas relativamente recientes, a familiares, les resulta imperioso mantener el contacto con el país de procedencia (Aja y Rodríguez 2017). 
¿UN DEBATE SUPERADO?

Sobre las bases expuestas, la situación más reciente de la migración cubana apunta hacia una nueva etapa, definida por contradicciones, en la que coexiste aún una cultura de intolerancia y un activismo político minoritario en sentido cuantitativo, pero con rasgos cualitativos de peso, junto a voces alternativas y rechazos al exilio histórico, cuya expresión en términos sociológicos es decreciente y se aleja cada vez más de lo que fue. Sus transformaciones tienen como telón de fondo los procesos de cambios que se han venido analizando (Pedraza 2015). Queda abierto un campo de análisis, reflexiones e interpretaciones. Se trata de un debate en curso. Las perspectivas se orientan hacia la profundización de las tendencias señaladas, es decir, hacia la continuidad de los cambios sociodemográficos, político-ideológicos e incluso, culturales, del exilio cubano, cuyas características generacionales implican la desaparición física de sus líderes históricos, una renovación de su estructura etaria, con predominio de jóvenes, con menor capacidad de comunicación en idioma español, en el caso de la descendencia de los primeros exiliados, sin conocimiento directo de la isla, pero a la vez, junto a crecientes figuras que han emigrado de Cuba en fechas recientes, marcados por la dinámica social establecida, en medio de muchas contradicciones, por la Revolución, que mantienen el contacto cotidiano con el mundo de familiares, amigos y vecinos que dejaron atrás.

De ahí que pueda afirmarse que, al examinar el momento político actual del exilio cubano, y al pensar en su evolución, habría que valorar una serie de factores que gravitarán sobre el futuro, que apuntan en su interrelación hacia dimensiones específicas que harán aún más compleja la cultura política de la migración en su conjunto y del exilio en particular, planteando interrogantes e hipótesis a su indagación y debate. Entre tales factores no pueden omitirse los siguientes: a) el proceso demográfico, de cambios generacionales: el envejecimiento de la primera generación, que ha sido base social del exilio histórico y de algunos segmentos de la izquierda, junto al auge natural de la segunda generación; b) el proceso de inserción, de integración social y cultural a la sociedad norteamericana 
receptora, principalmente en Estados Unidos, o sea la definitiva evolución del exilio hacia comunidad inmigrante y hacia grupo étnico; $c$ ) el proceso de transición específico que tenga lugar en el enclave de Miami, por su significado central para la comunidad cubana y el exilio histórico, que allí se forjó; d) la inyección de nuevos migrantes cubanos, con motivaciones y aspiraciones diferentes, así como con orientaciones ideológicas y compromisos políticos distintos; e) los procesos que tengan lugar en Cuba, junto a la percepción sobre los mismos en el exterior (Eckstein 2014).

Entretanto, la política de Estados Unidos hacia la isla arrecia su agresividad y enrarece el clima bilateral, del cual la migración ha sido, durante mucho tiempo, rehén inevitable. En Estados Unidos radica la mayor parte de los cubanos que residen en el exterior, alcanzan una cifra cercana a los 2 millones. Más allá de las raíces que se encuentran en la base de la historia del proceso migratorio cubano posterior al triunfo de la Revolución y del legado que llega al presente a través de sesenta años en los que la intolerancia satura las proyecciones hacia la isla, los cambios operados y los que se encuentran en curso propician un contexto objetivo y subjetivo que condiciona, o más exactamente, determina, la transición sociodemográfica, política y cultural de lo que ha sido el exilio histórico cubano, en el marco de la tercera década del siglo en curso (Duany 2017).

Como proceso que forma parte, en su sentido más amplio, de las migraciones latinoamericanas, cuyas tendencias históricas han seguido el trayecto sur-norte, conformando un patrón en el que las motivaciones económicas han tenido un sitio central, al que le acompañan el envío de remesas a los países de origen y conformando una migración de retorno, con circularidad, el cubano ha ido acercándose cada vez a ese patrón (Santana 2008). En la medida que pasan a un segundo orden las razones políticas y el carácter definitivo de la salida de la isla, la migración cubana incluye también el regreso y el sentido de brindar "ayuda" a las familias que quedan en Cuba.

La perspectiva futura de la migración cubana, empero, estará condicionada por los efectos que, del corto al mediano plazo pueda introducir la administración que se establezca como resultado de las elecciones de 
2020 en Estados Unidos (una permanencia de Trump en la Casa Blanca, de otra figura republicana, o resulte victorioso el candidato demócrata), y por el derrotero de la situación cubana bajo las nuevas estructuras de gobierno (en 2021 tendrá lugar el Congreso del Partido Comunista y se constará el éxito o fracaso del modelo económico en marcha).

BIBLIOGRAFÍA

Aja DÍAZ, ANTONio. Al cruzar las fronteras. La Habana: Editorial de Ciencias Sociales, 2014.

y María Ofelia Rodríguez Soriano. "La migración internacional de cubanos. Escenarios actuales". Novedades en Población 26 (2017).

ARBOleya Cervera, Jesús. Cuba y los cubanoamericanos. El fenómeno migratorio cubano. La Habana: Casa de las Américas, 2013.

CASTRO, MAX J. “HHabrá transición en la ideología del exilio?”. Temas 12-13 (1998).

Domínguez GuadarRama, RiCARDO. "Cuba y Estados Unidos: el largo camino del reconocimiento". Latinoamérica 60 (2015).

Domínguez López, ERNESTO, LANDY MACHADO CAjIDE y DALIA GONZÁLEZ DELGADO. "Nueva inmigración y comunidad cubana en Estados Unidos en los albores del siglo XXI". Migraciones Internacionales 84 (2016).

Duany, Jorge. "Cuban Migration: A Postrevolution Exodus Ebbs and Flows". Migration Information Source (2017).

ECKSTEIN, SuSAN. "La transformación de la diáspora y la transformación de Cuba". Woodrow Wilson Center Report On the Americas. Cambios en la sociedad cubana de los 9016 (2014).

Grenier, Guillemo y Lisandro PÉrez. The Legacy of Exile: Cubans in the United States. Boston: Allyn \& Bacon (New Immigrants Series), 2003. HERNÁNDEZ MarTíneZ, Jorge. "Antinomias en la cultura política de la emigración cubana en Estados Unidos". Temas 10 (1997). 
"El conflicto Cuba-Estados Unidos y la dinámica hemisférica: más allá de la coyuntura". Cuadernos Americanos 153 (2015).

Pedraza Bailey, Silvia, "Cuba's Exiles: Portrait of a Refugee Migration". The International Migration Revie 191 (2015).

PÉrez, LisAndro. "Cuban Americans and U.S. Cuba Policy". Josh DeWind and Renata Segura (ed.). Diaspora Lobbies and the U.S. Government: Convergence and Divergence in Making Foreign Policy. Nueva York: Nueva York University Press and the Social Science Research Council, N.Y., 2014.

RodrígueZ ChávEz, ERNESTO. "Determinantes de la emigración cubana actual y su impacto en la redefinición del fenómeno". Caderno CRH 3 (2000).

SANTANA, ADALBERTO (coord.). Proyección global de la migración latinoamericana. México: CIALC-UNAM, 2008. 